\title{
Role of Receptor-Interacting Protein 140 in human fat cells
}

\author{
Niklas Mejhert, Jurga Laurencikiene, Amanda T Pettersson, Maria Kaaman, Britta M Stenson, Mikael Rydén, \\ Ingrid Dahlman
}

\begin{abstract}
Background: Mice lacking Receptor-interacting protein 140 (RIP140) have reduced body fat which at least partly is mediated through increased lipid and glucose metabolism in adipose tissue. In humans, RIP140 is lower expressed in visceral white adipose tissue (WAT) of obese versus lean subjects. We investigated the role of RIP140 in human subcutaneous WAT, which is the major fat depot of the body.

Methods: Messenger RNA levels of RIP140 were measured in samples of subcutaneous WAT from women with a wide variation in BMI and in different human WAT preparations. RIP140 mRNA was knocked down with siRNA in in vitro differentiated adipocytes and the impact on glucose transport and mRNA levels of target genes determined.

Results: RIP140 mRNA levels in subcutaneous WAT were decreased among obese compared to lean women and increased by weight-loss, but did not associate with mitochondrial DNA copy number. RIP140 expression increased during adipocyte differentiation in vitro and was higher in isolated adipocytes compared to corresponding pieces of WAT. Knock down of RIP140 increased basal glucose transport and mRNA levels of glucose transporter 4 and uncoupling protein-1.

Conclusions: Human RIP140 inhibits glucose uptake and the expression of genes promoting energy expenditure in the same fashion as the murine orthologue. Increased levels of human RIP140 in subcutaneous WAT of lean subjects may contribute to economize on energy stores. By contrast, the function and expression pattern does not support that RIP140 regulate human obesity.
\end{abstract}

\section{Background}

Adipose tissue has a central role in regulating energy homeostasis. Maintenance of energy balance requires tightly regulated expression of gene networks that control metabolic functions in response to changing environmental conditions $[1,2]$.

Receptor-interacting protein 140 (RIP140) is a nuclear receptor corepressor that in mice is expressed in several organs; however the mRNA levels in white adipose tissue (WAT) are higher than in other metabolically active tissues, such as brown adipose tissue (BAT), muscle, and liver [3-5]. The physiological function of RIP140 has been tested in RIP140 knock out (RIPKO) mice. These mice have a reduced body weight and body fat content, when compared to wild-type (WT) mice [3]. The lean

\footnotetext{
* Correspondence: niklas.mejhert@ki.se

Department of Medicine, Huddinge, Lipid Laboratory, NVS, Karolinska
} Institutet, SE- 14186 Stockholm, Sweden phenotype of RIPKO mice is not explained by impaired adipogenesis, since RIP140 is not required for adipocyte differentiation [3]. Furthermore, RIPKO mice exhibit increased oxygen consumption, total fatty acid oxidation, glucose tolerance, insulin responsiveness upon high-fat feeding, and resistance to high-fat diet-induced obesity $[3,5]$. At the cellular level several genes, including cell death-inducing DFFA-like effector a (CIDEA), uncoupling protein-1 (UCP-1), and glucose transporter 4 (GLUT4) are upregulated in adipocytes from RIPKO as compared to WT-mice. Thus in mice RIP140 seems to play an important role in energy homeostasis which at least in part can be explained by its action on glucose uptake as well as lipid metabolism in white fat cells.

Surprisingly few studies have examined the expression of RIP140 expression in human organs. We therefore searched the GEO profiles database http://www.ncbi. nlm.nih.gov/ for RIP140 mRNA expression in the human transcriptome. According to record GDS596

C 2010 Mejhert et al; licensee BioMed Central Ltd. This is an Open Access article distributed under the terms of the Creative Commons 
RIP140 mRNA is widely expressed in different human tissues with particularly high expression levels observed in lung, skeletal muscle, reproductive organs and brain. It has recently been reported that RIP140 mRNA and protein levels are decreased in visceral WAT of morbidly obese as compared to lean humans implying that human RIP140 may, just as its rodent orthologue, regulate adipose tissue metabolism [6]. However, the function and expression of RIP140 mRNA in human subcutaneous WAT, which comprises the main store of body fat, has to our knowledge not been reported.

Caution should be exercised when extrapolating data from mice to man when adipose tissue is compared. For example there are major species differences in the regulation of lipid metabolism in fat cells [7]. This study was conducted with the aim of elucidating if RIP140 might be involved in the regulation of the subcutaneous fat mass in humans and if RIP140 had similar function in human white fat cells as in murine adipocytes. To accomplish this we investigated if RIP140 was present in human white fat cells and related the expression of RIP140 in human subcutaneous WAT to adiposity. In order to mimic the effect of gene knock out in mice we silenced RIP140 expression in human in vitro differentiated adipocytes and analyzed the effects of decreased mRNA levels of RIP140 on glucose transport and a set of genes involved in the control of energy homeostasis.

\section{Methods}

Subjects were recruited by local advertisement for the purpose of studying genes regulating obesity and fat cell function. Obesity was defined as having a BMI $\geq 30 \mathrm{~kg} /$ $\mathrm{m}^{2}$, whereas leanness was defined as having a BMI $\leq 25$ $\mathrm{kg} / \mathrm{m}^{2}$. Informed consent was received from all subjects involved in the study. The project was conducted in accordance with the guidelines in The Declaration of Helsinki and approved by the ethical committee at Karolinska University Hospital.

Paired samples of omental and abdominal subcutaneous WAT for mRNA measurements were available in cohort 1 comprising lean $(\mathrm{N}=11$; age $40 \pm 14$ years; BMI $\left.24 \pm 2 \mathrm{~kg} / \mathrm{m}^{2}\right)$ and obese $(\mathrm{N}=22$; age $43 \pm 9$ years; BMI $44 \pm 4 \mathrm{~kg} / \mathrm{m}^{2}$ ) women. The non-obese subjects were operated for uncomplicated gallstone disease and the obese with anti-obesity surgery as described previously [8]. These patients had been fasting overnight and only saline was given as an intravenous infusion until adipose tissue was removed [8].

Subcutaneous abdominal WAT biopsies for mRNA measurements were available from cohorts 2 and 3 . WAT (0.5-2 g) were obtained in the morning after an overnight fast from needle biopsies under local anesthesia as described previously [9]. Cohort $2(\mathrm{~N}=10$ women; age $39 \pm 6$ years; BMI $\left.40 \pm 6 \mathrm{~kg} / \mathrm{m}^{2}\right)$ were investigated before and after (1.5-4 years) weight reduction induced by intense anti-obesity therapy with antiobesity surgery or behavioral modification. All subjects became non-obese and were reinvestigated when they were weight-stable. These subjects have been described before [10]. Cohort 3 comprised 34 women with a wide variation in BMI $(\mathrm{N}=34$; age $42 \pm 12$ years; BMI $30 \pm$ $7 \mathrm{~kg} / \mathrm{m}^{2}$ ) for which relative amounts of mitochondrial DNA (mtDNA) to nuclear DNA in subcutaneous WAT were determined by quantitative RT-PCR. To investigate if RIP140 levels differed between genders we investigated three men before (age $37 \pm 11$ years; BMI $38 \pm 3 \mathrm{~kg} / \mathrm{m}^{2}$ ) and after the anti-obesity treatment described above under cohort 2 .

For the following adipocyte studies abdominal subcutaneous adipose tissue pieces were obtained as a waste product from plastic surgery. There was no selection on the basis of body fat content. WAT pieces were treated with collagenase as described elsewhere for isolation of the fat cells and the stroma vascular fraction, respectively [11]. Paired samples of isolated adipocytes and corresponding bits of subcutaneous WAT were available from five obese and five lean women (age $43 \pm 14$; BMI $28 \pm 6 \mathrm{~kg} / \mathrm{m}^{2}$ ). Cells harvested from the stroma vascular fraction were in vitro differentiated to adipocytes according to a method described previously [11]. RIP140 mRNA was quantified at day $4^{\text {th }}, 8^{\text {th }}$, and $12^{\text {th }}$ of differentiation in primary adipocyte cultures from eight women (age $46 \pm 13$ years; BMI $27 \pm 6 \mathrm{~kg} / \mathrm{m}^{2}$ ). in vitro differentiated adipocytes were prepared from five women (age $44 \pm 13$ years; BMI $26 \pm 2 \mathrm{~kg} / \mathrm{m}^{2}$ ) for siRNA and glucose transport experiments. RIP140 protein was detected in subcutaneous WAT from five women (age $32 \pm 4$ years; BMI $24 \pm 8 \mathrm{~kg} / \mathrm{m}^{2}$ ).

WAT samples were brought to the laboratory in saline and either used immediately for in vitro studies or frozen in liquid nitrogen, and stored at $-70^{\circ} \mathrm{C}$ until mRNA, DNA, and/or protein measurements were performed.

\section{Quantification of mitochondrial DNA copy number}

The ratio of mtDNA to nuclear DNA reflects the tissue concentration of mtDNA per cell and was determined by quantitative RT-qPCR as described. Briefly, a 120 nucleotide-long mtDNA fragment within the mitochondrial NADH dehydrogenase subunit 1 (ND1) gene was used for quantification of mtDNA. The PCR fragment has previously been cloned into a plasmid. Plasmid standards of known copy number were used to generate a log-linear standard curve, from which the ND1 copy numbers of studied samples could be determined by RT-qPCR. A 120 bp region of the nuclear gene lipoprotein lipase ( $L P L$ ) was used to normalize results. Plasmid standard curves containing the $L P L$ fragment were used to determine cell number of studied samples [12,13]. 


\section{Protein expression}

Approximately $300 \mathrm{mg}$ of subcutaneous WAT was lysed in $600 \mu \mathrm{l}$ protein lysis buffer (1\% Triton-X 100 , Tris$\mathrm{HCl} \mathrm{pH} 7.6$ and $150 \mathrm{mmol} / \mathrm{L} \mathrm{NaCl}, 4^{\circ} \mathrm{C}$ ), supplemented with protease inhibitors $(1 \mathrm{mmol} / \mathrm{L}$ phenylmethylsulfonyl fluoride and Complete ${ }^{\bullet}$ (Boehringer, Mannheim, Germany)), and homogenized. The lysed tissue was centrifuged at 14000 RPM for 30 minutes after which the infranatant was collected. Protein content was assayed spectrophotometrically using the BCA Protein Assay Reagent Kit (PIERCE, Rockford, IL) on 96-well microtiter plates with bovine serum albumin (BSA) (SIGMA, St Louis, MO) as standard. To test if proteins remained in the fat cake following protein extraction the fat cake was removed and subjected to methanol-chloroform (Merck, Darmstadt, Germany) extraction which effectively collects all proteins [14]. These extracted proteins were dissolved in $600 \mu \mathrm{l}$ protein lysis buffer (same as above). Protein levels in fat cake extracts were below the detection limit. After optimization the following conditions were chosen. $100 \mathrm{mg}$ of total cellular protein was loaded on polyacrylamide gels and separated by standard $10 \%$ sodium dodecyl sulphate-polyacrylamide gel electrophoresis. Preadipocytes were used as a negative control since RIP140 expression is induced in later stages of differentiation. Gels were transferred to polyvinylidine fluoride membranes (Amersham Biosciences, Little Chalfont, UK). For RIP140 detection the blot was blocked for $1 \mathrm{~h}$ at room temperature in Tris-buffered saline with $0.1 \%$ Tween-20 (TBS-T) and 3\% BSA (SIGMA). This was followed by an overnight incubation at $4^{\circ} \mathrm{C}$ in the presence of $4 \mu \mathrm{g} / \mathrm{ml}$ antibody directed against RIP140 (R 5027, SIGMA). The following day the membrane was rinsed in TBS-T and secondary $\alpha$-rabbit antibodies conjugated to horseradish peroxidase (SIGMA) were added. The membrane was incubated in room temperature for one hour and after that rinsed with TBS-T. Antigen-antibody complexes were detected by chemiluminescence using a kit from LumiGLO ${ }^{\circ}$ (Cell Signaling Technology, Danvers, MA) and specific bands were detected using a Chemidoc XRS system (Bio-Rad Laboratories Inc., Hercules, CA).

\section{Small interfering RNA mediated knock down}

Cells harvested from the stroma vascular fraction obtained after collagenase treatment of subcutaneous WAT were in vitro differentiated to adipocytes according to a method described previously [11] and treated with siRNA as described [15]. Briefly, 200000 cells/well were seeded in a 12 -well plate and in vitro differentiated for twelve days at $37^{\circ} \mathrm{C}$ in $5 \% \mathrm{CO}_{2}$. On the tenth day of differentiation cells were treated with $100 \mathrm{nM}$ ON-TARGETplus SMARTpool RIP140 (L-006686-00) small interfering RNA (siRNA) (Thermo Fisher Scientific, Lafayette, CO) and $9 \mu$ l HiPerFect Transfection Reagent
(Qiagen, Hilden, Germany) according to the manufacturer's protocols. These conditions were chosen after careful optimization. To control for unspecific effects of siRNA treatment, control cells were treated with AllStars Negative Control siRNA (Qiagen). After 48 hours cells were lysed for isolation of RNA using $350 \mu$ lysis buffer containing RA1 lysis buffer (Macherey-Nagel, Duren, Germany) and $3.5 \mu \mathrm{l} \beta$-mercaptoethanol.

\section{Glucose uptake}

In vitro differentiated human adipocytes were treated with RIP140 or non-silencing siRNA as described above. 48 hours post transfection cells were washed with glucose-free DMEM (Biochrom, Berlin, Germany) and incubated at $37^{\circ} \mathrm{C}$ for three hours in medium consisting of 1:1 glucose-free DMEM and HAM/F12 (Gibco, Invitrogen, Carlsbad, CA). To determine net insulin effect on glucose transport, insulin was added to cells at a final concentration of $10^{-6} \mathrm{M}$ followed by incubation at $37^{\circ} \mathrm{C}$ for 15 minutes. One $\mu \mathrm{Ci}$ of 2-Deoxy-D- [1-3H] glucose (Amersham Biosciences) per $1 \mathrm{ml}$ medium was added to the cells followed by 20 minutes incubation at $37^{\circ} \mathrm{C}$. Cells were washed in ice cold PBS, lysed in $0.1 \%$ SDS- $\mathrm{H}_{2} \mathrm{O}$, and radioactivity was measured in liquid scintillant in a $\beta$-counter 1214 Rackbeta LKB (Wallac, PerkinElmer Life Sciences, Waltham, MA) the following day. RNA preparation

Total RNA was extracted from isolated adipocytes (200 $\mu \mathrm{l}$ ) and corresponding pieces of subcutaneous WAT (300 mg), as well as in vitro differentiated adipocytes $(200 \mu \mathrm{l})$ using the NucleoSpin ${ }^{\odot}$ RNA II (MachereyNagel) kit. RNA concentration and purity was measured spectrophotometrically using a Nanodrop ND-1000 Spectrophotometer (Thermo Fisher Scientific). Half a microgram of total RNA was reverse transcribed using Omniscript First-strand cDNA synthesis kit (Qiagen) and random hexamer primers (Invitrogen). RNA purified from in vitro differentiated adipocytes were reversed transcribed using iScript ${ }^{\mathrm{Tm}} \mathrm{cDNA}$ synthesis kit (Bio-Rad Laboratories Inc.), with some modifications. Purified total RNA, RNase-free water, and $5 \times$ iScript reaction mixes were preheated for 15 minutes at $55^{\circ} \mathrm{C}$. After preheating tubes were put on ice for one minute and iScript reverse transcriptase was added.

\section{Quantitative real time PCR}

For TaqMan assays 10 ng of cDNA was mixed with $2 \times$ TaqMan Universal PCR Master Mix (Applied Biosystems, Foster City, CA) and TaqMan ${ }^{@}$ Gene Expression Assays (Applied Biosystems) in a final volume of $20 \mu \mathrm{l}$. mRNA was analyzed for RIP140 (Hs00942766_s1), glucose transporter 1 (GLUT1) (Hs00197884_m1), GLUT4 (Hs00168966_m1), CIDEA (Hs00154455_m1), UCP-1 (Hs00222453_m1), PPAR $\gamma$ co-activator 1 a (PGC-1 $\alpha)$ (Hs00173304_m1), low density lipoprotein receptorrelated protein 10 (LRP10) (Hs00204094_m1), and $18 S$ 
(Hs99999901_s1). For SYBR Green assays, 5 ng of cDNA was mixed with $2 \times$ iQ SYBR Green Supermix (Eurogentec S.A., Ougrée, Belgium) and primers (Invitrogen) in a final volume of $25 \mu$ l. Primer pairs were designed to span exon-intron boundaries and to be specific for the mRNA to be amplified according to BLAST searches. The following primers were used for specific mRNA quantification: RIP140 (forward primer 5'-TGA CCA AAA CCA ACC CAA TAC T-3', reverse primer 5'-GAC CTG TGA GAC ACT TTC AGC A-3'), PPAR $\gamma$ (forward primer 5'-ACA AGG CCA TTT TCT CAA ACG-3', reverse primer 5'-CGG AGA GAT CCA CGG AGC-3'), hormone-sensitive lipase (HSL) (forward primer 5'-GGA AGT GCT ATC GTC TCT GG-3', reverse primer 5'-GGC AGT CAG TGG CAT CTC-3'), LRP10 (forward primer 5'-GAT GGA GGC TGA GAT TGT G-3', reverse primer 5'-GAG TCA TAT CCT GGC GTA AG-3'), and $18 S$ (forward primer 5'-TGA CTC AAC ACG GGA AAC C-3', reverse primer 5'-TCG CTC CAC CAA CTA AGA AC-3'). Dissociation curve analyses and agarose gel electrophoresis were used to validate that one single amplicon was amplified. Quantitative real-time PCR was performed using an iCycler $\mathrm{IQ}^{\mathrm{Tm}}$ (Bio-Rad Laboratories Inc.). PCR efficiency in all runs was close to $100 \%$ and samples were run in duplicate. Expression of mRNA was normalized to an internal reference gene, $18 S$ (isolated adipocytes and corresponding bits of subcutaneous WAT) or LRP-10 (in vitro differentiated adipocytes) by using a comparative $\mathrm{Ct}$ method, i.e. $2^{\Delta \mathrm{Ct} \text {-target gene }} / 2^{\Delta \mathrm{Ct} \text {-reference gene }}$. The patient with the highest $\mathrm{Ct}$ value for the target gene was used as a calibrator from which all other $\mathrm{Ct}$ values for the target gene and reference gene, respectively, were subtracted.

\section{Statistical analysis}

The mRNA levels between two groups were compared with paired Student's t-test. When comparing three groups, results were evaluated with ANOVA. Correlation between RIP140 mRNA levels and mtDNA copy number was studied with multiple regression analysis with age and BMI as covariate. If necessary, RIP140 levels were $\log _{10}$-transformed to become normally distributed. Values were presented as mean \pm SD. All statistics were calculated with Statview (version 5.01, SAS Institute, Cary, NC).

\section{Results}

\section{Subcutaneous WAT RIP140 mRNA levels are inversely} correlated to obesity

We first assessed abdominal subcutaneous WAT RIP140 mRNA levels in relationship to adiposity. RIP140 mRNA levels were decreased approximately $50 \%$ in obese compared to lean women in subcutaneous WAT (cohort 1, $\mathrm{P}<0.001$ ) (Figure 1A). We also confirmed decreased levels (25\%) of RIP140 mRNA in visceral WAT of obese subjects (cohort $1, \mathrm{P}<0.01$ ) (Figure $1 \mathrm{~A}$ ). Levels of RIP140 mRNA were lower in visceral as compared to subcutaneous WAT, and this was due to a difference in lean subjects only (Figure 1A). No difference between WAT depots were observed in obese subjects. Expression of RIP140 mRNA in subcutaneous WAT increased 2.5-fold after long term weight-loss to a weight-stable, lean state (cohort $2, \mathrm{P}<0.01$ ) (Figure $1 \mathrm{~B}$ ). There was no difference in RIP140 mRNA expression between genders before (women $0.11 \pm 0.34$ vs. men $0.09 \pm 0.13 \log _{10}$ $\mathrm{AU}$ ) or after (women $0.42 \pm 0.10$ vs. men $0.30 \pm 0.12$ $\left.\log _{10} \mathrm{AU}\right)$ weight-loss.

Considering that RIP140 has been implicated in regulation of energy expenditure and mitochondrial function in mice, we related subcutaneous WAT RIP140 mRNA levels to mtDNA copy number, which is a simple measure of mitochondrial mass that can be used to screen mitochondrial content in a large number of samples [5,13]. RIP140 mRNA levels in subcutaneous WAT did not associate with mtDNA copy number in 34 investigated women (results not shown).

\section{RIP140 MRNA and protein in WAT}

We next evaluated the distribution of RIP140 in subcutaneous WAT. RIP140 mRNA expression was increased almost twofold in isolated adipocytes compared to corresponding intact pieces of WAT $(\mathrm{P}<0.001)$ (Figure $2 \mathrm{~A})$. Furthermore, obesity was associated with reduced levels of RIP140 mRNA in adipocytes (obese $\mathrm{N}=5,0.87$ $\pm 0.12 \log _{10}$ AU vs. lean $\mathrm{N}=5,1.12 \pm 0.10 \log _{10} \mathrm{AU}, \mathrm{P}$ $>0.01$ ). During in vitro human adipocyte differentiation RIP140 levels were up-regulated during the $8^{\text {th }}$ and $12^{\text {th }}$ day compared to the $4^{\text {th }}$ day of differentiation $(\mathrm{P}<$ 0.001 for both). There was no significant change in expression when comparing the $8^{\text {th }}$ and $12^{\text {th }}$ day (Figure 2B). RIP140 protein was detected by western blot analysis in subcutaneous WAT with preadipocytes as a negative control (Figure 3).

RIP140 knock down increases glucose uptake and expression of UCP-1 and GLUT4

To elucidate the biological role of RIP140 we silenced RIP140 in in vitro differentiated human adipocytes by siRNA. Depletion of RIP140 mRNA levels was confirmed by real-time PCR to be significantly knocked down by $\sim 80 \%(\mathrm{p}<0.01)$ (Figure $4 \mathrm{~A})$. We then investigated how this knock down affected glucose transport and mRNA levels for a set of genes involved in glucose metabolism and energy expenditure. Basal glucose transport was significantly up regulated in RIP140 knock down adipocytes compared to cells transfected with non-silencing siRNA $(\mathrm{p}<0.05)$, while the net insulin effect was unaffected (Figure 4B). In general, insulin-stimulated glucose uptake was significantly higher than basal glucose uptake in non-silencing as well as RIP140 

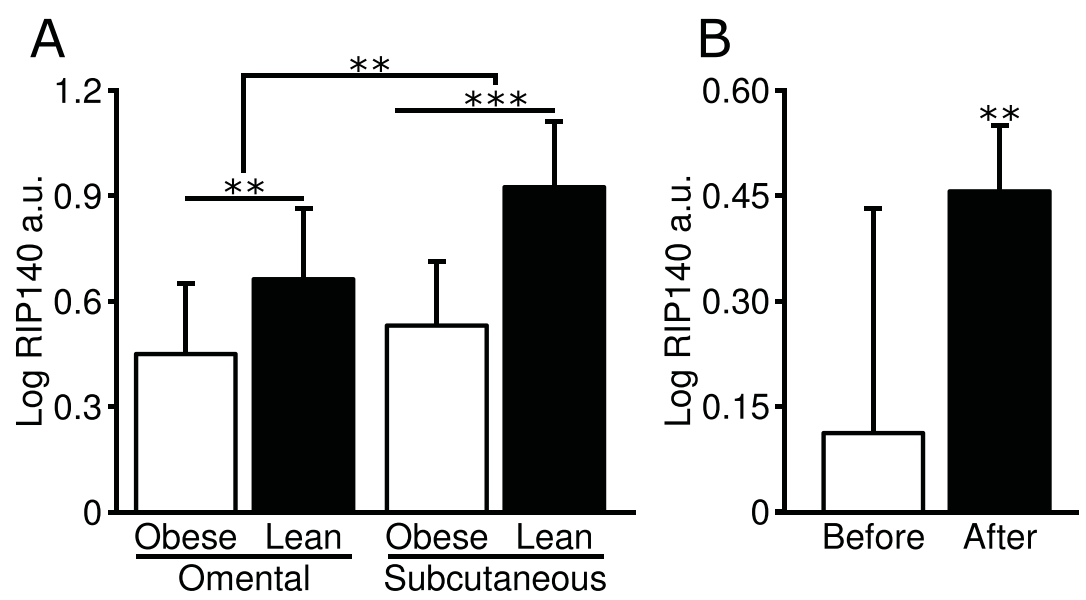

Figure 1 RIP140 mRNA expression in human WAT and obesity. A) RIP140 mRNA levels were measured in omental and subcutaneous WAT from 22 obese and 11 lean women. B) Subcutaneous WAT RIP140 mRNA levels were investigated before and after weight-loss to a weightstable non-obese state (subjects, $N=10$ ). All samples were run in duplicate and normalized to the reference gene 18S. Arbitrary units (a.u.) are presented as mean \pm standard deviation and were $\log _{10}$-transformed to become normally distributed. ${ }^{*}, \mathrm{P}<0.01$ and ${ }^{* * *}, \mathrm{P}<0.001$.

siRNA transfected cells and individuals with high basal glucose uptake had high insulin stimulated glucose uptake.

RIP140 silencing significantly increased mRNA levels of GLUT4 and UCP-1 compared to control cells ( $\mathrm{P}<$ 0.01 for both) (Figure 4C). Fold change vs. non-silencing control siRNA was for GLUT4 7.2 \pm 1.7 and for UCP-1 $32.2 \pm 14.5$. A trend toward increased mRNA levels for GLUT1 and CIDEA was observed $(\mathrm{P}=0.0594$ and $\mathrm{P}=$ 0.052 , respectively). Fold change vs. non-silencing control siRNA was for GLUT1 $2.1 \pm 1.0$ and for CIDEA $3.5 \pm 2.2$. In contrast, $P G C-1 \alpha, P P A R \gamma$, and HSL mRNA levels remained unchanged (Figure $4 \mathrm{C}$ ).

\section{Discussion}

To the best of our knowledge this is the first study investigating the function of RIP140 in human subcutaneous WAT, which is the major fat depot of the body. In mice it appears that the RIP140 is involved in glucose metabolism and energy expenditure of WAT $[3-5,16,17]$.
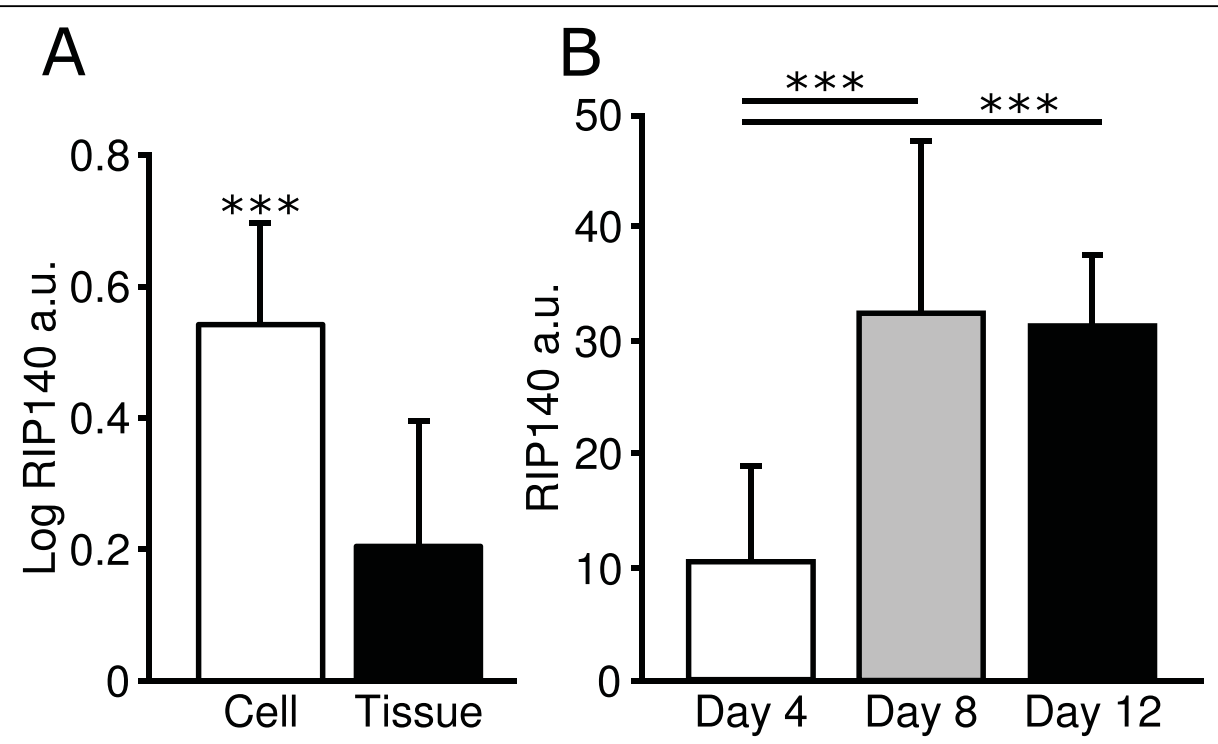

Figure 2 Localization of human RIP140 in WAT. A) RIP140 mRNA levels were measured in isolated adipocytes and corresponding bits of subcutaneous WAT from ten women. B) RIP140 mRNA expression was quantified at the $4^{\text {th }}, 8^{\text {th }}$, and $12^{\text {th }}$ day of adipocyte differentiation in vitro. RIP140 arbitrary units (a.u.) were calculated as $2^{\Delta \mathrm{Ct} \text {-target gene/ }} 2^{\Delta \mathrm{Ct}-\text { reference gene }}$ using $18 \mathrm{~S}$ (isolated adipocytes and corresponding WAT) and LRP10 (cultured adipocytes) as reference genes. Values are presented as mean \pm SD and were $\log _{10}$-transformed to become normally distributed when needed. ${ }^{* *}, \mathrm{P}<0.001$. 


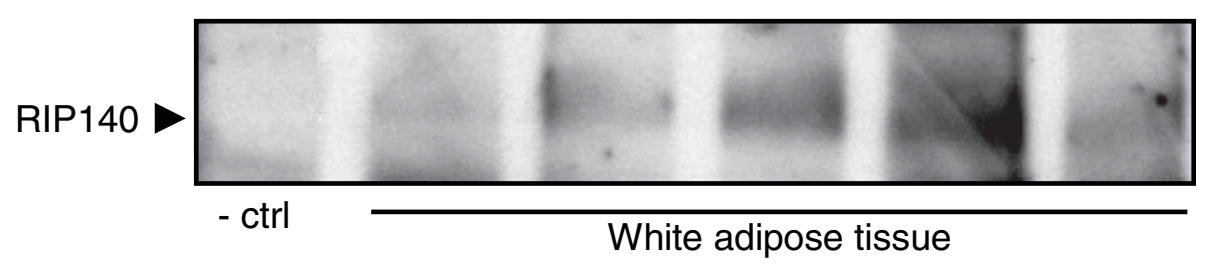

Figure 3 Detection of RIP140 protein with Western blot in subcutaneous WAT of five women. Preadipocytes were used as a negative control (-ctrl).

We have shown that RIP140 mRNA levels in subcutaneous WAT, as has previously been reported for visceral WAT [6], are inversely correlated with measures of adiposity and are enriched in fat cells of adipose tissue. Moreover, RIP140 reduce basal glucose transport and expression of the genes GLUT4 and UCP-1.

RIP140 is enriched in isolated fat cells than intact WAT. This suggests that its major function is confined to the adipocytes of WAT although a role in stroma vascular cells is not to be excluded. Furthermore, human RIP140 mRNA expression increased during adipocyte differentiation, which is in agreement with results in mice $[3-5,18]$. Since mouse RIP140 has no impact on the differentiation process, we focused on the importance of RIP140 for metabolism in the differentiated human white fat cells. Silencing of RIP140 increased basal glucose transport, but had no impact on the effect of insulin on glucose uptake. In 3T3-L1 adipocytes, inhibition of RIP140 by siRNA has been reported to increase insulin-stimulated glucose uptake [5]. However, at an early stage of adipocyte differentiation, basal glucose uptake was also increased [5]. Furthermore, we observed that primarily mRNA levels of the glucose transporter GLUT4 but not GLUT1 were increased by RIP140 silencing in human fat cells, which is in line with data from knock out mice [5]. An impact on GLUT1 expression could not be excluded but was marginal compared to the impact on GLUT4 expression. Thus, it appears that RIP140 in both human and mice acts as an inhibitor of glucose uptake although there may be some differences in the action of insulin on glucose uptake between the different in vitro cell systems. The mechanisms leading to increased basal glucose transport in RIP140-depleted human adipocytes are unknown. Potential mechanisms involve post-translational effects on GLUT1 protein or involvement of other GLUT-proteins. Additional experiments are needed to elucidate how RIP140 regulates basal glucose uptake. Similarly, additional experiments are necessary to clarify whether GLUT4 is directly regulated by RIP140 and what other transcriptional regulators are involved, or if altered GLUT4 expression is mediated through changes in adipocyte metabolism. In 3T3-L1 adipocytes, the effects of RIP140 on glucose uptake are at least partly mediated via the transcription factor Estrogen-related receptor alpha (ERR $\alpha)$ [5]. ERR $\alpha$ is an important regulator of genes in energy metabolism [5]. Loss of ERR $\alpha$ prevents increased GLUT4 expression and deoxyglucose uptake in RIP140 depleted adipocytes. Furthermore, ERR $\alpha$ expression is increased in RIP140depleted adipocytes [5].
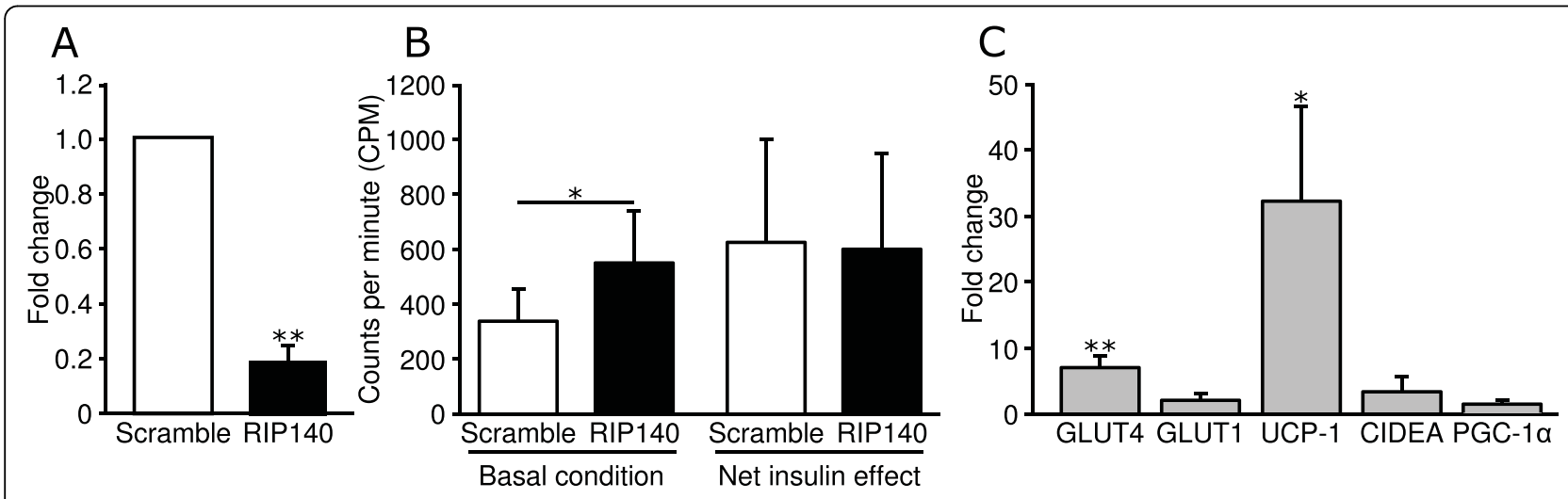

Figure 4 Effect of RIP140 silencing on human in vitro differentiated adipocytes. A) RIP140 mRNA levels in RIP140 siRNA and non-silencing siRNA (scramble) treated cells. B) Glucose transport, measured as counts per minute (CPM), was determined 48 hours post siRNA transfection. Net insulin effect was calculated by subtracting insulin-stimulated glucose uptake with basal glucose uptake. C) Specific mRNA levels were measured $48 \mathrm{~h}$ after siRNA mediated RIP140 knock down. In A and C, values are presented as fold change versus non-silencing siRNA (scramble). Data presented are mean \pm SD of five independent experiments. ${ }^{*}, P<0.05$ and ${ }^{* *}, P<0.01$. 
RIP140 silencing in human in vitro differentiated adipocytes led to increased mRNA levels of $U C P-1$, but not $P G C-1 \alpha, P P A R \gamma$, and HSL. These results confirm previous data from knock out mice [3,4]. The up-regulation of CIDEA expression was non-significant in our study $(\mathrm{P}=0.0525)$. However, it is quite conceivable that RIP140 regulates CIDEA expression in human WAT since our results are in line with previous observations in mice [3-5]. In a one sided analysis, which is justified for confirmatory data, CIDEA mRNA levels were induced significantly by RIP140 silencing $(\mathrm{P}<0.05)$. Altogether, RIP140 had a smaller impact on CIDEA mRNA levels in humans as compared to mice. One possible explanation for this discrepancy is the difference in CIDEA expression between mice and human. Human $C I D E A$ is expressed in WAT in contrast to mice where $C I D E A$ is widely expressed in BAT but most often not detected in WAT [19-21]. UCP-1 encodes a member of the mitochondrial proton carrier family of proteins and is expressed in BAT, but only to a limited extent in WAT [22]. Elevated $U C P-1$ levels are thought to convert WAT towards a browner phenotype by allowing mitochondrial respiration to occur in the absence of ATPsynthesis with dissipation of the produced energy as heat. CIDEA has also been implicated as a regulator of energy expenditure in both mice and humans $[21,23]$. Thus, our results support the notion that inhibition of human RIP140, similar to the murine homologue, increases the expression of genes involved in the regulation of energy expenditure. In our study we found no association between RIP140 mRNA levels and mtDNA copy number, which is in agreement with a study performed in mice [4]. This together with the elevated levels of UCP-1 suggests that RIP140 influences the function of existing mitochondria rather than biogenesis.

As has previously been reported in visceral WAT [6], abdominal subcutaneous RIP140 mRNA levels were reduced in obesity. Considering the functions ascribed to lack of RIP140 in in vitro studies, i.e. increased glucose uptake and elevated energy expenditure, it is difficult to link reduced RIP140 levels in obesity with a primary role in adiposity. We therefore consider the alternative that the physiological role of increased levels of RIP140 in lean subjects functions to economize on energy stores more likely. On the other hand, down regulation of RIP140 in obesity could be accompanied by changes in expression of other transcription factors and co-factors, which could lead to a different metabolic outcome than down regulation of RIP140 in cell cultures.

\section{Conclusion}

In conclusion, in agreement with its mouse homologue human RIP140 is involved in the control of energy homeostasis of white fat cells by inhibiting glucose uptake and genes regulating energy expenditure. Furthermore, increased RIP140 expression in lean and after weight reduction may be a mechanism to economize on energy stores. By contrast, the function and expression pattern does not support that RIP140 regulate human obesity.

\section{Acknowledgements}

We thank Gaby Åström, Elisabeth Dungner, Kerstin Wåhlen, Eva Sjölin, Katarina Hertel, and Britt-Marie Leijonhufvud for excellent technical assistance. This study was supported by the Swedish Research Council, NovoNordisk Foundation, Swedish Heart and Lung Foundation, EndoMet, Karolinska Institutet, the European Union [HEPADIP (LSHM-CT-2005-018734), COST action BM0602, and ADAPT (HEALTH-F2-2008-201100], NordForsk (SYSDIET-070014), and the Magnus Bergwall's, Ake Wiberg's and Golje's foundations.

\section{Authors' contributions}

All authors have read and approved the manuscript. NM and ID have made substantial contributions to the study design, acquisition and analysis of data. JL, BMS and MR participated in the optimization of the western blot and the CDNA-synthesis as well as revised the manuscript. ATP and MK participated in the design of the siRNA and mtDNA copy number experiments and helped to draft the manuscript.

\section{Competing interests}

The authors declare that they have no competing interests.

Received: 21 July 2009

Accepted: 29 January 2010 Published: 29 January 2010

\section{References}

1. Spiegelman BM, Flier JS: Obesity and the regulation of energy balance. Cell 2001, 104(4):531-543.

2. Sonoda J, Pei L, Evans RM: Nuclear receptors: decoding metabolic disease. FEBS Lett 2008, 582(1):2-9.

3. Leonardsson G, Steel JH, Christian M, Pocock V, Milligan S, Bell J, So PW, Medina-Gomez G, Vidal-Puig A, White R, et al: Nuclear receptor corepressor RIP140 regulates fat accumulation. Proc Natl Acad Sci USA 2004, 101(22):8437-8442.

4. Christian M, Kiskinis E, Debevec D, Leonardsson G, White R, Parker MG RIP140targeted repression of gene expression in adipocytes. Mol Cell Biol 2005, 25(21):9383-9391.

5. Powelka AM, Seth A, Virbasius JV, Kiskinis E, Nicoloro SM, Guilherme A, Tang X, Straubhaar J, Cherniack AD, Parker MG, et al: Suppression of oxidative metabolism and mitochondrial biogenesis by the transcriptional corepressor RIP140 in mouse adipocytes. J Clin Invest 2006, 116(1):125-136

6. Catalan V, Gomez-Ambrosi J, Lizanzu A, Rodriguez A, Silva C, Rotellar F, Gil MJ, Cienfuegos JA, Salvador J, Fruhbeck G: RIP140 Gene and Protein Expression Levels are Downregulated in Visceral Adipose Tissue in Human Morbid Obesity. Obes Surg 2009.

7. Arner P: The adipocyte in insulin resistance: key molecules and the impact of the thiazolidinediones. Trends Endocrinol Metab 2003, 14(3):137-145

8. Arner P, Stenson BM, Dungner E, Naslund E, Hoffstedt J, Ryden M, Dahlman I: Expression of six transmembrane protein of prostate 2 in human adipose tissue associates with adiposity and insulin resistance. $J$ Clin Endocrinol Metab 2008, 93(6):2249-2254.

9. Kolaczynski JW, Morales LM, Moore JH Jr, Considine RV, Pietrzkowski Z, Noto PF, Colberg J, Caro JF: A new technique for biopsy of human abdominal fat under local anaesthesia with Lidocaine. Int $J$ Obes Relat Metab Disord 1994, 18(3):161-166.

10. Lofgren P, Andersson I, Adolfsson B, Leijonhufvud BM, Hertel K, Hoffstedt J, Arner $\mathrm{P}$ : Long-term prospective and controlled studies demonstrate adipose tissue hypercellularity and relative leptin deficiency in the postobese state. J Clin Endocrinol Metab 2005, 90(11):6207-6213. 
11. van Harmelen V, Dicker A, Ryden $M$, Hauner $H$, Lonnqvist $F$, Naslund $E$, Arner P: Increased lipolysis and decreased leptin production by human omental as compared with subcutaneous preadipocytes. Diabetes 2002, 51(7):2029-2036.

12. He L, Chinnery PF, Durham SE, Blakely EL, Wardell TM, Borthwick GM, Taylor RW, Turnbull DM: Detection and quantification of mitochondrial DNA deletions in individual cells by real-time PCR. Nucleic Acids Res 2002, 30(14):e68.

13. Bogacka I, Xie H, Bray GA, Smith SR: Pioglitazone induces mitochondrial biogenesis in human subcutaneous adipose tissue in vivo. Diabetes 2005, 54(5):1392-1399.

14. Tansey JT, Sztalryd C, Gruia-Gray J, Roush DL, Zee JV, Gavrilova O, Reitman ML, Deng CX, Li C, Kimmel AR, et al: Perilipin ablation results in a lean mouse with aberrant adipocyte lipolysis, enhanced leptin production, and resistance to dietinduced obesity. Proc Natl Acad Sci USA 2001, 98(11):6494-6499.

15. van Harmelen V, Eriksson A, Astrom G, Wahlen K, Naslund E, Karpe F, Frayn $\mathrm{K}$, Olsson $\mathrm{T}$, Andersson J, Ryden $\mathrm{M}$, et al: Vascular peptide endothelin-1 links fat accumulation with alterations of visceral adipocyte lipolysis. Diabetes 2008, 57(2):378-386.

16. Christian M, White R, Parker MG: Metabolic regulation by the nuclear receptor corepressor RIP140. Trends Endocrinol Metab 2006, 17(6):243-250.

17. Parker MG, Christian M, White R: The nuclear receptor co-repressor RIP140 controls the expression of metabolic gene networks. Biochem Soc Trans 2006, 34(Pt 6):1103-1106.

18. Soukas A, Socci ND, Saatkamp BD, Novelli S, Friedman JM: Distinct transcriptional profiles of adipogenesis in vivo and in vitro. $\mathrm{J} \mathrm{Biol} \mathrm{Chem}$ 2001, 276(36):34167-34174.

19. Moraes RC, Blondet A, Birkenkamp-Demtroeder K, Tirard J, Orntoft TF, Gertler A, Durand P, Naville D, Begeot M: Study of the alteration of gene expression in adipose tissue of diet-induced obese mice by microarray and reverse transcription- polymerase chain reaction analyses. Endocrinology 2003, 144(11):4773-4782.

20. Nordstrom EA, Ryden M, Backlund EC, Dahlman I, Kaaman M, Blomqvist L, Cannon B, Nedergaard J, Arner P: A human-specific role of cell deathinducing DFFA (DNA fragmentation factor-alpha)-like effector A (CIDEA) in adipocyte lipolysis and obesity. Diabetes 2005, 54(6):1726-1734.

21. Zhou Z, Yon Toh S, Chen Z, Guo K, Ng CP, Ponniah S, Lin SC, Hong W, Li P: Cidea-deficient mice have lean phenotype and are resistant to obesity. Nat Genet 2003, 35(1):49-56.

22. Oberkofler $H$, Dallinger G, Liu YM, Hell E, Krempler F, Patsch W: Uncoupling protein gene: quantification of expression levels in adipose tissues of obese and non-obese humans. J Lipid Res 1997, 38(10):2125-2133.

23. Laurencikiene J, Stenson BM, Arvidsson Nordstrom E, Agustsson T, Langin D, Isaksson B, Permert J, Ryden M, Arner P: Evidence for an important role of CIDEA in human cancer cachexia. Cancer Res 2008, 68(22):9247-9254.

\section{Pre-publication history}

The pre-publication history for this paper can be accessed here:http://www. biomedcentral.com/1472-6823/10/1/prepub

doi:10.1186/1472-6823-10-1

Cite this article as: Mejhert et al.: Role of Receptor-Interacting Protein

140 in human fat cells. BMC Endocrine Disorders 2010 10:1.

\section{Submit your next manuscript to BioMed Central and take full advantage of:}

- Convenient online submission

- Thorough peer review

- No space constraints or color figure charges

- Immediate publication on acceptance

- Inclusion in PubMed, CAS, Scopus and Google Scholar

- Research which is freely available for redistribution

Submit your manuscript at www.biomedcentral.com/submit
C) Biomed Central 